\title{
Design and Evaluation of Spatial Multi Interaction Interface
}

\author{
Chang Ok Yun \\ Arcade Game Regional Innovation Center \\ Dongseo University \\ Busan, Korea
}

\author{
Tae Soo Yun, YoSeph Choi \\ Division of Visual Contents \\ Dongseo University \\ Busan, Korea
}

\begin{abstract}
Nowadays interactive displays are capable of offering a great variety of interactions to users thanks to advancement of ubiquitous computing technologies. Although many methods of interactions have been researched, usability of the devices is still limited and they are offered only to a single user at a time. This paper proposes a spatial multi-interaction interface that can provide various interactions to many users in an ambient environment. An interaction surface is created for users to interact through IR-LEDs Array Bar. The coordinate information of the hand is extracted by detecting the area of the hand of a user in the interaction surface. Then users can experience various interactions through "spatial touches" on the interaction surface. In our paper a usability evaluation is carried out for our new interface which gives the emphasis to the interaction interface. The usability of our new interface is shown to be significantly better through statistical testing using t-testing. Finally, users can perform various interactions with natural hand motions only without the aid of devices that have to be operated manually.
\end{abstract}

\section{Keywords-Interactive display; Ambient environment; Interaction surface; Spatial interaction}

\section{INTRODUCTION}

Until very recently, development of ubiquitous computing technologies has been focusing on building infrastructures such as constructing communication networks in the areas where human activities are possible, but now attention is focused on multi-modal interaction technologies with which humans can interact naturally with the computing environment built by the communications infrastructure. To construct an "ambient" or "disappearing" computing environment" which characterizes the ubiquitous display, a system has been developed which offers different interactions depending on the distance between users(Stephanidis, 2009). The existing technology only offers either a simple touch type of display or grasps the user's intention using various sensors, but now "Gossip Wall" makes use of distance sensors, and the interactive ambient display system collects and shares the position information of the user through various cameras. The problem with the interaction devices that use the existing technology is that it is unable to provide natural interactions to users. Moreover, it is a sensor recognition method; therefore, users have to install sensor recognition devices. Thus many users cannot participate all together. In other words, since the existing technology uses traditional devices such as keyboards and mouse, most interactions are limited to certain areas that are directly related to these devices. To overcome these limitations of the existing techniques, it is now necessary to develop a new technology that can control the components more naturally and intuitively in an ambient environment as well as a new method of showing relevant information more effectively to users.

This paper proposes an interactive system with which humans can interact using simple hand movements alone without the aid of sensor recognition devices in a ubiquitous ambient environment. The proposed system differs from the existing interaction and the operation of space interaction. Whereas in the traditional technology, a single user interacts using an interaction device (a mouse) that is connected to a computer, in the proposed spatial multi-interaction system, a number of users can interact in the space with a variety of contents by using only simple hand movements. This paper is organized as follows. Section 2 describes previous researches on various interaction techniques in an ambient environment. Section 3 describes the design and implementation of the proposed interface. Section 4 describes the result of the proposed technique and the experimental environment. Section 5 gives a comparative analysis of the proposed system and the existing system. Finally, Section 6 closes the paper with conclusions.

\section{RELATE WORKS}

The Ambient Intelligence (AmI) provides electronic environments that are sensitive and responsive to the presence of people. The ISTAG played a decisive role in the further development of the AmI vision and launched a scenario planning exercise to demonstrate what might be realised through AmI technology (IST Advisory Group, 2003). The users are provided with applications and services with which they interact in unobtrusive manner (Aarts, Harwig \& Schuurmans 2003). In the AmI, the sensors are used to be supported and utilized in the interaction, and applications and services should be consistent, easy to handle and easy to learn. Furthermore, devices are wirelessly connected and form intelligent networks which create environments in which people are surrounded by intelligent and intuitive interfaces that are embedded in all kinds of objects (Holmlid, S. \& Björklind, A. (2003)). And the AmI will be performed with the aim of hiding the presence of technology to the users, providing seamless and unobtrusive interaction paradigms.(Stephanidis, 2009).

The University of Toronto developed an interactive ambient display for public use, which interacts with users in four stages in accordance with the distance between the user and the 
display. Users can have a different interaction in each stage (Vogel \& Balakrishnan, 2004). However, interactions are limited because the user must wear many types of recognition devices, and it is difficult for multiple users to use the system. Norbert A. Streitz, et al. of Fraunhofer IPSI has attempted to advance interactions from human-computer interaction (ICI) to human-environment interaction (HEI). Through their research products such as Roomware(Tandler, 2004) and Ambient Agoras(Streitz, 2007), they tried to integrate the space made up of actual structure which has inherent computing ability and virtual information space. Stanford University's iRoom (Johanson, 2002) has presented a new type of interacting method whose purpose is to develop a display for public use in cooperative environment. Gossip Wall developed by Fraunhofer IPSI in Germany is one of the many techniques of using various devices that have been researched. When the user is in an ambient environment that is very far away from the display, general information is displayed, and when the user comes close to the display and the display recognizes the user, the display shows contents that are relevant to the user. When the user comes very close and walks into the interaction area, the user can use the display of the mobile device to get detailed information. It is also possible to connect with outside. In the case of Gossip Wall, the user uses a mobile device that employs a distance sensor system to get the needed information, and the display grasps the position of the user. However, the problem with Gossip Wall is that it can trace the user only when the user carries the mobile device. Another problem is that the available display devices are limited in variety.

Recently in Korea, various researches are in progress on the application of infrared LED to the sensing systems. Tracking technique that makes use of infrared LED is applied to the mutual interactions between the interface and users (Kim \& Kim, 2009), and a rehabilitation training system is being developed by applying the infrared LED band (Park \& Park, 2008). In the case of Nintendo Company, the immersive user interface (Yoon et al., 2009) is offered by tracing the gaze and the location of the user, applying the Wii controller and infrared LED. In another case, a variety of contents are offered through a simple pointing and controlling device (Hong et al., 2009; Baek et al., 2005; Park \& Park, 2008) that uses infrared LED. In still other case, FTIR (Frustrated Total Internal Reflection)-based tabletop displays and interactive wall displays (Choi et al., 2008) are developed, and they are being applied to various contents. In short, the existing interaction interface using the infrared LED contains inconvenient and restricting elements.

Touchless interaction techniques (Barrée et al., 2009), by allowing user to employ hand gestures, remove the burden related to physical contact and promote natural interaction with digital information made tangible through large display surfaces. Touchless interaction can also be multimodal: in this case the interaction events embrace different human senses (visual, auditory and olfactory). Most of the emergent game devices come from the entertainment industry, such as: Nintendo's Wii Remote Controller, Microsoft's Project Natal and Sony Play Station3 Motion Sensing controller.
There are more intuitive motion-based interactions such as detection of natural body movement. Besides providing a more intuitive game playing (Vaughan-Nichols, 2009) (not only based on button pushing), these devices also stimulate the development of touchless interfaces that go beyond interaction styles using WIMP (Windows, Icons, Mouse and Pointers) elements. Don't Touch Me(Bellucci et al., 2010) is a system providing the users with the possibility to collaborate, generate and place multimodal annotation on a digital map using Nintendo's Wiimote. And the rapid prototyping of touchlessenabled interfaces(Lee, 2008) is providing the feasibility of the Nintendo's Wiimote. A 3D vision-based ambient user interface(Hong \& Woo, 2006) as an interaction metaphor that exploits a user's personal space and its dynamic gestures is the system of touching the augmented SpaceSensor. The eye-gaze input system(Murata, 2006) is using as one of the touchless interaction interface. The system is providing conditions such as the moving distance, size of a target, and direction of movement in a pointing task.

Consequently, the user either has to carry simple pointing or control devices or touch the display directly. This paper proposes a spatial multi interaction interface in which users can interact with the display through the interaction surface created at the IR-LEDs Array Bar using only natural hand motions without any devices that have to be operated manually..

\section{Spatial Multi Interaction Interface}

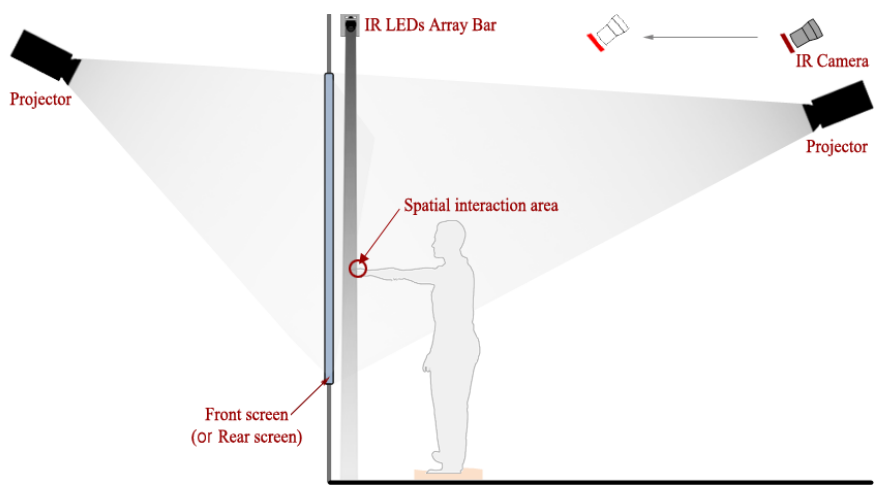

Fig. 1. The overall system layout.

Fig. 1 shows the overall layout of a large scale interactive display which offers a variety of spatial multi interactions to users. This system consists of a large projector-based wallsurface display device, IR LEDs Array Bar that uses an IRLEDs generating device, and an IR Camera equipped with an IR-Filter. As can be seen in Fig. 1, the user interacts by using hand motions in a natural way on the IR interaction surface, but not on the restricted screen of the existing display. In the environment of our system, the distance from the user and screen is changed according to IR LEDs Array Bar location. Spatial interaction area in the range to reach the hands (the range of people reaching out), the interaction is enough. In addition, our system arranged the camera and projector in the front side of user considering the case where the person competes for the projector and the screen used the Rear Screen and solved the phenomenon that this system is covered by the user body. 
And this system was shrouded through the location change of the camera (Adjust the distance between the camera and screen, the camera focal length adjustment), it concluded the problem.

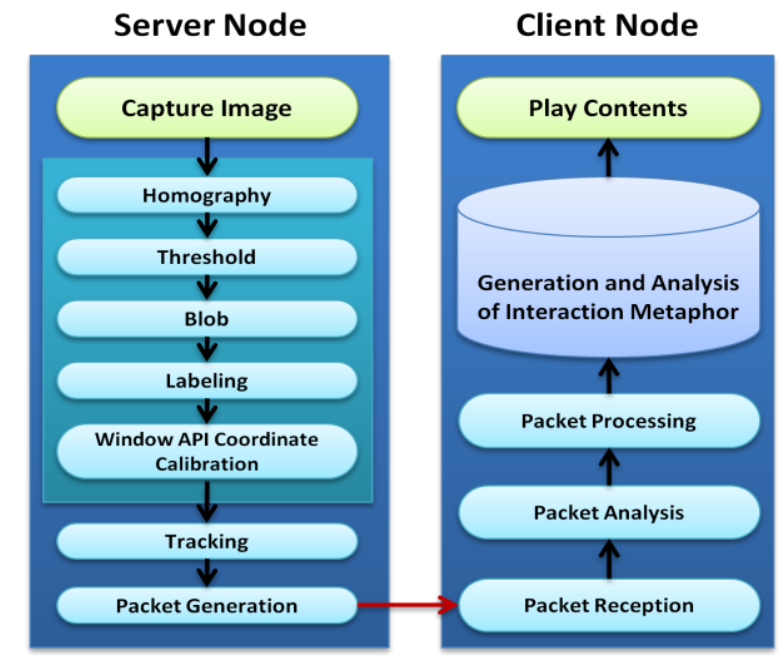

Fig. 2. Flowchart of the System.

Fig. 2 shows the overall flowchart of the proposed spatial multi-interaction interface. First, the IR camera inputs the image. Since the image obtained through the camera is generally distorted, the image is revised by using the homography matrix. To remove any noise other than a certain intensity of illumination, the threshold process is used to remove noise. After the coordinates are revised in the bloblabeling process, the position of the hand is located through tacking. This information on the hand coordinates applies spatial multi-interaction through the client (contents) and network communications.

\section{A. Environmental Setup for Image Getting}

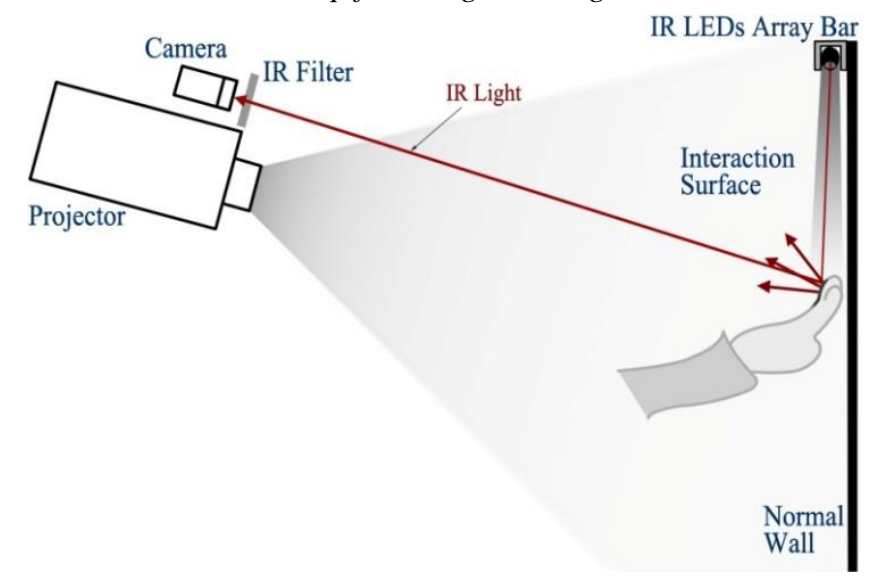

Fig. 3. Positions of the Projector and Camera.

The proposed system does not require a special screen, but an IR-LEDs array bar is installed on the upper end of the screen in proportion to the width of the screen. The distance of the projector is determined in proportion to the size of the screen. The bigger the screen, the further away is the projector from the screen, and the smaller the screen, the closer to the screen is the projector positioned. Thus, it can be installed any place using various spaces. Moreover, since the proposed system uses the touchless mode, it can recognize the user's gestures in space and makes it possible for the user to interact in a natural and comfortable way. In other words, even when the interaction surface is separated from the wall, the user can do spatial interactions on the interaction surface and enjoy a variety of contents. The camera is placed above the projector so that it can see the projected area on the screen. At this point, the images coming out of the projector are cut off by using the Band-pass filter because without the use of Band-pass filter, all images projected by the projector would appear on the screen. The Band-pass filter cuts off areas smaller than $850 \mathrm{~nm}$ [see Fig. 3].

In this work, the IR-LEDs array bar was installed to fit the width of the screen for spatial multi-interaction interface. The IR-LEDs array bar was constructed by arranging IR LED with intervals of $3 \mathrm{~cm}$. The screen and infrared rays must be kept horizontal so that images of everything and anything unnecessary except the realm of the user's hand are removed. To maintain the horizon, the radiation scope of lights was narrowed by cutting off the vicinities of IR LED. To prevent infrared rays from radiating to $45^{\circ}$, both edges of LED were cut off so that rays would radiate vertically. Fig. 4(b) shows an IRLEDs array bar using light straight. To track the user's hand, the IR-LEDs array bar radiates light rays vertically downward from the top of the screen. When the light rays reach the user's hand, light rays cannot travel in straight lines because of the hand. As a result the light rays that lost the ability to travel in straight lines remain on the back of the user's hand, and the infrared camera obtains the location of the hand. The infrared LED used for this purpose radiates light waves of $45^{\circ} 880 \mathrm{~mm}$.
(a)ordinary IR LED
(b) IR LED Array Bar

Fig. 4. IR LED Array Bar that uses the principle of light rays traveling in straight lines.

\section{B. Image Distortion Correction}

In general, a system that uses a projector and a camera requires a stage of revision to get the coordinate value of the exact position.

If the coordinate for the hand is calculated on the basis of the distorted image as shown in Fig. 5(b), applying it to the screen coordinate, it is not possible to get the right result. Therefore, after getting the image input by the camera, the keystones for the image to be projected through the projector are corrected and the homographic relations are calculated for 
the images to be projected. Following these procedures, it is possible to obtain information on the exact coordinate of the image projected by the camera as shown in Fig. 5 (c). There are two ways of calculating conversion relations between the camera's image and the projector's image: The fundamental matrix that calculates the epipolar geometry between the two images projected by the camera and the projector, and the homographic matrix that measures the relations of dots between two planes. The fundamental matrix deals not with the relations between dots but with the relations between dots and planes. Thus it suffers from severe noise because it has to consider many planes, and consequently, it produces more noise than the homographic matrix. Taking these problems into consideration, this paper applies homography to calculate the conversion relations between the camera and the projector. With these findings, distorted images are corrected.

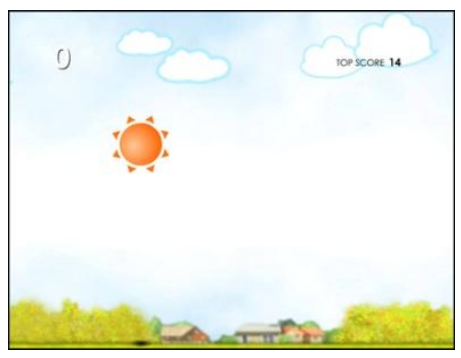

(a) Input image by the projector
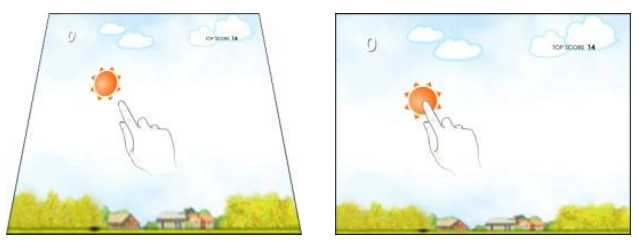

(b)Distorted input image

(c) Input image corrected

Fig. 5. Input image corrected by homography.

The homographic method is capable of calculating geometric projective relations between two planes as follows. The relation between the input image's coordinate $X_{i}^{\prime}=\left(x_{i}{ }^{\prime}, y_{i}{ }^{\prime}, w_{i}{ }^{\prime}\right)^{T}$ and the converted output image can be presented with the following equation.

$$
\left(\begin{array}{c}
x_{i}{ }^{\prime} \\
y_{i}{ }^{\prime} \\
w_{i}{ }^{\prime}
\end{array}\right)=\left(\begin{array}{lll}
h_{1} & h_{2} & h_{3} \\
h_{4} & h_{5} & h_{6} \\
h_{7} & h_{8} & h_{9}
\end{array}\right)\left(\begin{array}{c}
x_{i} \\
y_{i} \\
w_{i}
\end{array}\right)
$$

Eq. (1) can be simplified as $X_{i}{ }^{\prime}=H X_{i}$ where $H$ is a homography with a size of $3 \times 3$, and Eq. (1) can be transformed as Eq. (2).

$$
X_{i}^{\prime} H X_{i}=0
$$

Eq. (2) is developed with $A h=0$, and $A$ can be calculated as follows:

$$
A=\left[\begin{array}{ccccccccc}
0 & 0 & 0 & -x_{1} & -y_{1} & -1 & y_{1}{ }^{\prime} x_{1} & y_{1}{ }^{\prime} y_{1} & y_{1}{ }^{\prime} \\
x_{1} & y_{1} & 1 & 0 & 0 & 0 & -x_{1}{ }^{\prime} x_{1} & -x_{1} y_{1} & -x_{1}{ }^{\prime} \\
0 & 0 & 0 & -x_{2} & -y_{2} & -1 & y_{2}{ }^{\prime} x_{2} & y_{2}{ }^{\prime} y_{2} & y_{2}{ }^{\prime} \\
x_{2} & y_{2} & 1 & 0 & 0 & 0 & -x_{2}{ }^{\prime} x_{2} & -x_{2}{ }^{\prime} y_{2} & -x_{2}{ }^{\prime} \\
\vdots & \vdots & \vdots & \vdots & \vdots & \vdots & \vdots & \vdots & \vdots \\
0 & 0 & 0 & -x_{n} & -y_{n} & -1 & y_{n}{ }^{\prime} x_{n} & y_{n}{ }^{\prime} y_{n} & y_{n}{ }^{\prime} \\
x_{n} & y_{n} & 1 & 0 & 0 & 0 & -x_{n}{ }^{\prime} x_{n} & -x_{n}{ }^{\prime} y_{n} & -x_{n}{ }^{\prime}
\end{array}\right]
$$

$h$ is $9 \times 1$ vector which is $H$ matrix arranged in dictionary sort, and $A$ is the $n \times 9(n \geq 4)$ matrix which is the combination of $X_{i}$ and $X_{i}^{\prime}$. $A$ has 8 degrees of freedom and so it requires at least 4 pairs of coordinates. $h$ consists of Eigenvectors which correspond to the smallest Eigenvalue of $A^{T} A$. The elements of $h$ thus calculated are substituted with each element of homography in order. Fig. 6 shows the homographic relations of the corresponding points between the images of the screen, the projector, and the images.

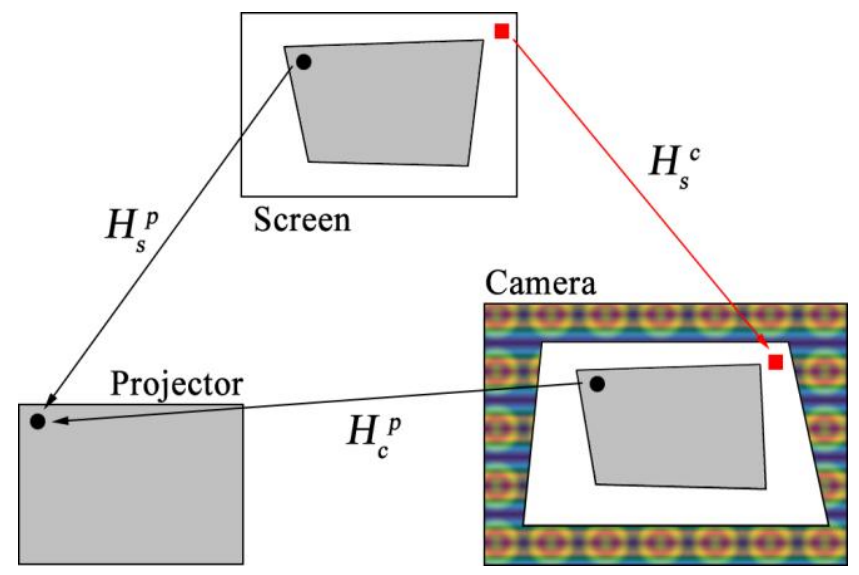

Fig. 6. Projector-Camera Homography Relations.

$H_{s}^{p}$, the homographic relations between the images to be projected by the camera and the images to be projected by the projector, must be calculated in order to correct the keystones of the images to be projected after getting the input from the camera. If the boundary line ratios that form the 4 vertexes on the screen and the coordinates of the vertexes that are fixed on the camera are known, the homography $H_{s}^{c}$ can be calculated. 
In addition, if the rates are known for the images that are to be projected from the projector and if the coordinates of the four vertexes that are fixed on the camera are already known, $H_{c}^{p}$, the homography between the camera and the projector can be calculated. Therefore, $H_{s}^{p}$, the homography between the screen and the projector can be obtained via Eq. (5) if $H_{s}^{c}$, the homography between the screen and the camera, $H_{c}^{p}$, the homography between the camera and the projector $H_{c}^{p}$ are already known.

$$
H_{s}^{p}=H_{s}^{c} H_{c}^{p}
$$

\section{Correction of Mouse Coordinate}

Coordinates obtained through homography calculation are the coordinates in the realm of the camera's view, and they are not the coordinates that are actually applied to the window's coordinate. If the camera's entire view area is $640 * 480$ and the resolution is $1024 * 768$, the error range will inevitably be big. To reduce the margin of errors in the position information, the mouse's range is calculated at the API level and the window's coordinate is controlled.

$$
\begin{aligned}
& X_{k}=X_{i} \times \frac{65535}{\text { width }} \\
& Y_{k}=Y_{i} \times \frac{65535}{\text { height }}
\end{aligned}
$$

Since the actual coordinate of the mouse has the area of $0 \sim$ 65535 (up, down, right and left) regardless of the resolution, the current resolution 65535 is divied by the width and height and multiplied by the coordinate $\left(X_{i}, Y_{i}\right)$ which is the result of homography calculation. Then the right coordinate is calculated. (Refer to Eq. (6))

\section{Multi-interaction for publicly shared space}

A spatial multi-touch function is essential for various interactions. Spatial multi-touch means that the input information appears simultaneously in many parts of the screen. In the proposed system, the information that is input through the band pass filter is binary coded [Fig. 7(a)] and the noise is removed. Each position is located in the blob-labeling process [Fig. 7(c)].

Computers being used currently do not have the device to simultaneously input many kinds of information and they are incapable of performing a spatial multi-interaction function. For this purpose, the network communication is used to communicate with the system and the contents. The coordinate sought out by the infrared camera forms packets and transmits the contents in real time. The contents analyze the packets transmitted and implement the spatial multi-interaction function.

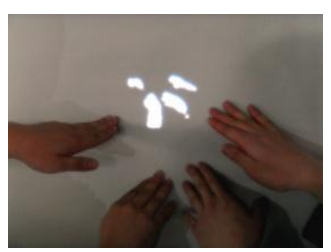

(a) Recognition of the finger contact area

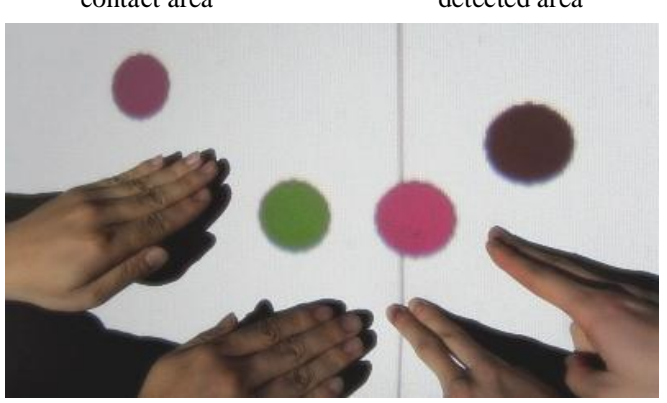

(c) Implementation of the multi-interaction function applied to the applied contents
Fig. 7. The hand area recognition and Blot treatment of relevant area using infrared rays and the result of Blob treatment of the relevant area.

\section{EXPERIMENTAL INTERFACE AND RESULTS}

\section{A. Experimental Set-Up}

The proposed system was implemented using Microsoft Visual $\mathrm{C}++$, OpenCV on a system in which a Pentium IV $1.8 \mathrm{GHz}, 2 \mathrm{~GB}$ RAM is installed. After obtaining the camera's images, treating the images, correcting the distorted images, and recognizing coordinates by using Visual $\mathrm{C}++$ language, it is now possible for users to interact with the contents through the network communication. In the proposed system, the camera gets the information on the user's position by recognizing the IR rays reflected on the interaction surface that is created by the IR-LEDs Array Bar. The surrounding environmental conditions for the proposed system can influence the performance of the system; therefore, the experimental environment was designed by eliminating these negative environmental factors. Osram 880nm IR LED was used to construct the IR-LEDs Array Bar. An 850nm IR filter was used as a means of inputting the IR images only. To get the IR area images effectively inputted, the IR cutoff filter attached to the front of the CCD was removed before the experiment. All the images coming out of the projector are cut off by using a band pass filter (the filter that cuts off waves shorter than $850 \mathrm{~nm})$, and only the IR rays are accepted. As a result, when the user puts out a hand toward the interaction surface in order to interact the contents, the infrared light coming down from the IR-LEDs Array Bar are cut off because it cannot penetrate the hand. At this point, the camera finds out the coordinate information by processing the infrared light reflected from the hand into images. The IR-LEDs Array Bar was constructed by arranging infrared LED with $3 \mathrm{~cm}$ intervals. To enforce straight traveling, both sides of infrared LED were cut off so that the infrared light that used to radiate out to $45^{\circ}$ will only travel vertically downward. Fig. 8 presents the overall experimental environment for the proposed system. 


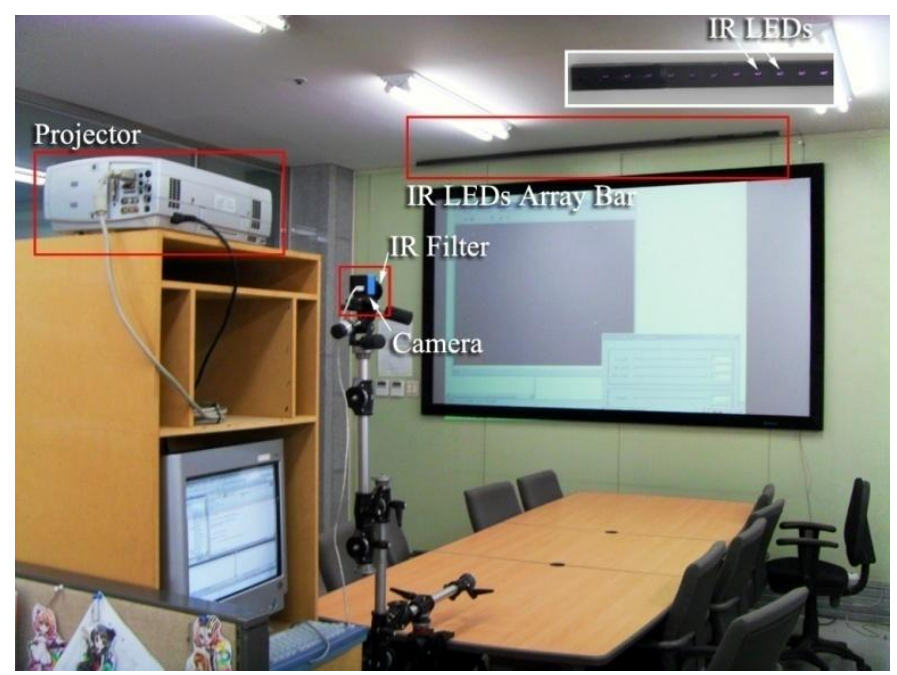

Fig. 8. The experimental environment for the proposed system.

\section{B. Results of Performance Evaluation}

The functions of devices composing the recognition system are important factors determining the function of the entire interaction face because the recognition function of the interaction interface influences the usability.

The existing system that typically can be easily accessed by the user is pressure-sensitive touch screen. The differences between the proposed and existing systems are as follows:

TABLE I. DIFFERENCES BETWEEN PROPOSED AND EXISTING SYSTEM

\begin{tabular}{|c||c|c|}
\hline Item & Proposed system & Existing system \\
\hline $\begin{array}{c}\text { Recognition } \\
\text { method }\end{array}$ & Camera based & Pressure-sensitive \\
\hline Size & More than 120 inches & $17,24,42$ inch \\
\hline Multi Touch & Possible & Possible(one dual touch) \\
\hline Strength & $\begin{array}{c}\text { High scalability(Large) } \\
\text { Wall type } \\
\text { Lower cost } \\
\text { Easy to implement }\end{array}$ & $\begin{array}{c}\text { Convenient access } \\
\text { Easy to use }\end{array}$ \\
\hline Weakness & $\begin{array}{c}\text { Need to learn about the basic } \\
\text { functions }\end{array}$ & Not scalable \\
\hline
\end{tabular}

In this study we calculated the FPS (frames per second) of touches made by the user to measure the function of the entire recognition system. Hands on comparing the number of existing systems can be up to two touching a proposed system to support two or more the number of touches. In other words, the speed can be faster for two, but that does not support more than the number of touch.

TABLE II. TOUCH RECOGNITION SPEED(FPS)

\begin{tabular}{|c|c|c|c|c|c|c|c|c|c|c|c|c|c|}
\hline \multicolumn{2}{|c|}{ Number of hands } & 1 & 2 & 3 & 4 & 5 & 6 & 7 & 8 & 9 & 10 & 11 & 12 \\
\hline \multirow{2}{*}{$\begin{array}{c}\text { Recognition } \\
\text { speed } \\
\text { (fps) }\end{array}$} & $\begin{array}{c}\text { Proposed } \\
\text { system }\end{array}$ & 30 & 30 & 30 & 30 & 30 & 30 & 29 & 29 & 29 & 29 & 29 & 29 \\
\hline & $\begin{array}{c}\text { Existing } \\
\text { system }\end{array}$ & 50 & 50 & - & - & - & - & - & - & - & - & - & - \\
\hline
\end{tabular}

The high intensity of the light from the IR LED BAR is so strong that it creates a film. Light that is emitted at a certain wavelength and intensity spreads evenly over the interaction film. Thus interactions were achieved on the entire interaction area. The result of the camera frame test showed an efficiency of 30fps over the entire area, and it was confirmed that the interactions were tracking naturally without pause to the eyes of the user. Furthermore, as shown in Fig. 9, many users can interact in space on a large scale interactive display environment. A high efficiency of 21-30 fps was maintained while multi-users were interacting.

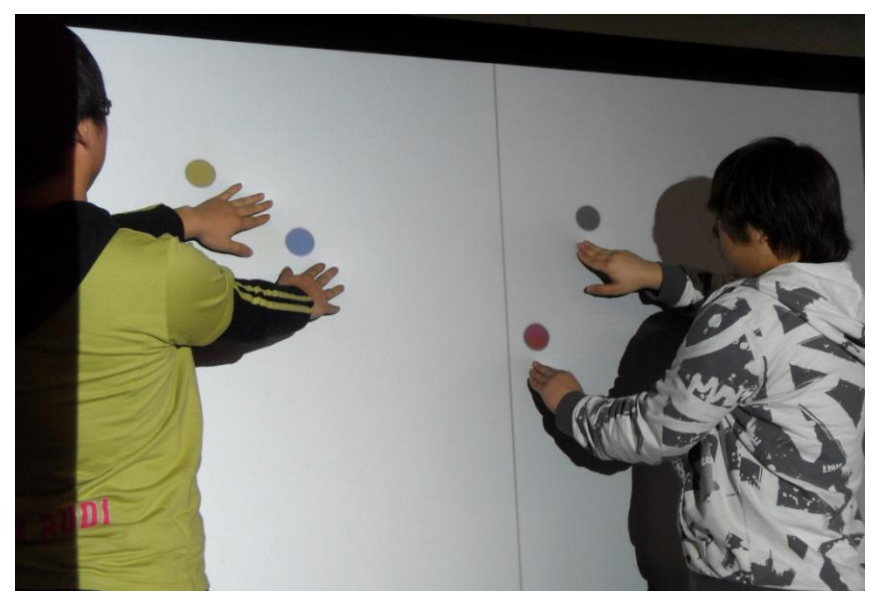

Fig. 9. Spatial multi-interaction demonstration.

To evaluate the recognition ability, the speed of hand area recognition was measured. It takes approximately $0.01 \mathrm{msec}$ to capture an image through the recognition camera, including the time required for basic image capturing, pre-treatment of every recognition process, and GUI generating process. As listed in Table 2, the time required for recognizing the hand motion is about $0.01 \mathrm{msec}$ for as many as 9 hand areas. When the hand areas increase to 10 , the time required to recognize the image increases to $0.02 \mathrm{msec}$.

\section{TABLE III. HAND AREA RECOGNITION TIME}

\begin{tabular}{|c||c||c|c|c|c|c|c|c|c|c|c|c|c|}
\hline \multicolumn{2}{|c|}{ Number of hands } & 1 & 2 & 3 & 4 & 5 & 6 & 7 & 8 & 9 & 10 & 11 & 12 \\
\hline $\begin{array}{c}\text { Recognition } \\
\text { time } \\
\text { (msec) }\end{array}$ & $\begin{array}{c}\text { proposed } \\
\text { system }\end{array}$ & 0.01 & 0.01 & 0.01 & 0.01 & 0.01 & 0.01 & 0.01 & 0.01 & 0.01 & 0.02 & 0.02 & 0.02 \\
\hline $\begin{array}{c}\text { Existing } \\
\text { system }\end{array}$ & 0.005 & 0.005 & - & - & - & - & - & - & - & - & - & - \\
\hline
\end{tabular}

\section{Evaluation of Usability}

The proposed system offers an interface with which the user can interact in space on an ambient environment display. This system is expected to be fabricated and implemented more easily and naturally than the existing multi-touch method. In the proposed system, interaction is made possible by the position of the hand whereas in the existing multi-touch screen system, interaction is carried out by touching the screen directly. To examine how the spatial multi-interaction interface is received by the users, this section evaluates the usability compatibility of the game contents developed for the proposed system with those of the existing multi-touch screen method. Thus, the user's satisfaction is measured. 


\section{A. Purpose of Evaluation}

According to the research purpose of the newly developed ambient environment display, we compared the proposed system with the existing touch display (type 1) and measured the degree of satisfaction the users felt on "ease of use" and "learnability" of the two displays.

1) Ease of Use : "How easily and freely can users use the contents?"is the question to answer here. Ease and freedom include both the convenience of inputting viewed from the perspective of hardware and the user's sensory perception of control in using the contents. Contents of the game are implemented totally by the user's choice and control. The inconvenience or limitations felt by the users give the users an impression that they are not in complete control of the game, and perceived inconvenience and limitations immediately lower the user's interest in the contents. The 'Ten Usability Heuristics' of Jakob Neilsen widely applied to the evaluation of software and websites also point out that usability is on the top of the list of requirements for interface.

2) Learnability of Use : "High learnability" of contents means that the user can use the contents intuitively with the least of amount of learning. Many options in using the contents and non-intuitive methods require users to learn many things, and this is directly linked to lowering of users' interest. Previous studies including Jacob Neilsen's 'Recognition rather than recall'(Neilsen, 1994) all emphasize the importance of usability. Especially in the games characterized by play and immediate interaction, an increase in the amount of learning "how to play?" plays the role of a fatal factor that lowers the interest in the contents.

\section{B. Method of Evaluation}

Ease of use and learnability of the ways to play the contents that apply the proposed system are compared to those of the existing multi-touch screen method to measure the degree of satisfaction felt by the users. The 50 developers evaluated using the Heuristic Evaluation method prepared in advance. Developers who participated in the evaluation were composed of professionals(almost workers) and amateurs(almost students). Through questionnaires to the participants before the experiment existing touch screen interface and a development interface for use in the survey was conducted, the user enough information on how to use them after the experiment was performed as described. For each interface using the time to consider the content Running time was 5 minutes. The amount of playing the contents is totally three times.

TABLE IV. EVALUATION PARTICIPANTS(50 DEVELOPERS

\begin{tabular}{|c||c|c|c|c|c|}
\hline Item & $\begin{array}{c}\text { Online game } \\
\text { developers }\end{array}$ & $\begin{array}{c}\text { Console game } \\
\text { developers }\end{array}$ & UI developers & $\begin{array}{c}\text { Network } \\
\text { developers }\end{array}$ & $\begin{array}{c}\text { Web contents } \\
\text { developers }\end{array}$ \\
\hline Count & 16 & 12 & 8 & 8 & 6 \\
\hline
\end{tabular}

Heuristic Evaluation method (Neilsen, 1994) is more efficient in cost, evaluation time, and manpower required for evaluation than other evaluation methods because exact heuristics are applied on the objects to be measured. Since the purpose of this evaluation is to find out the strengths as well as the weaknesses of the game contents that are newly developed, the Lickertis scale was used to record the degree of satisfaction which the participants felt on all the items on the list. In this evaluation, the scale of 1-7 is applied instead of the 1-5 scale which is more widely used, since in the 1-5 scale, results tend to center around 3 ("fair" satisfaction, neither good nor bad).

The game content used for the evaluation is a matching game for two or more nursery school age children in which a dam is rebuilt and destroyed. The party who scores more points within a given time is the winner. The higher scoring determines the winner and the loser. The game is played by multi-touch inputting and dragging.

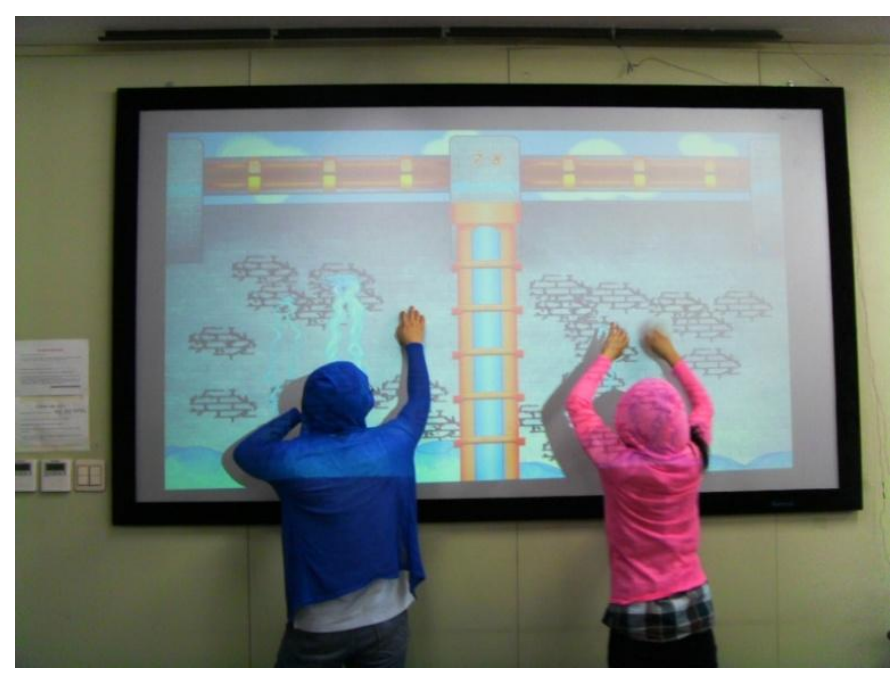

Fig. 10. Experimenting multi-touch matching game.

C. Establishing the evaluation heuristics

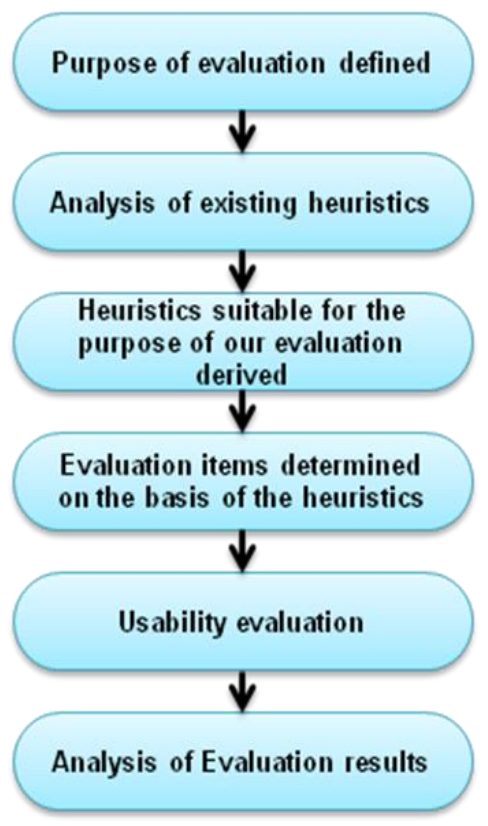

Fig. 11. User evaluation process

Our evaluation heuristics, "ease of use and learnability of operation method", are derived from Jacob Neilsen's 'Ten 
Usability Heuristics' which are widely used for evaluating the usability of software and websites and Melissa A .Federoff's 'Game Heuristics'(Federoff, 2002) which studied the usability of game contents.

We quote the following two comments by Jacob Neilsen on "User control and freedom" and "Recognition rather than recall".

TABLE V. CRITERIA FOR USABILITY EVALUATION

\begin{tabular}{|c|c|}
\hline \multirow[b]{2}{*}{1} & User control and freedom \\
\hline & $\begin{array}{l}\text { Users often choose system functions by mistake and will need a } \\
\text { clearly marked "emergency exit" to leave the unwanted state without } \\
\text { having to go through an extended dialogue. Support undo and redo. }\end{array}$ \\
\hline & Recognition rather than recall \\
\hline 2 & $\begin{array}{l}\text { Minimize the user's memory load by making objects, actions, and } \\
\text { options visible. The user should not have to remember information } \\
\text { from one part of the dialogue to another. Instructions for use of the } \\
\text { system should be visible or easily retrievable whenever appropriate. }\end{array}$ \\
\hline
\end{tabular}

Neilsen's "User control and freedom" is pointing out the need to support "Undo" and "Redo" functions in order that gamers can use the contents freely even after they make mistakes in inputting (Nielson, 1993). Neilsen is recommending here the functions that are not directly related to contents. However, they are important in controlling the contents and using them freely(Federoff, 2002) because if users feel inconvenient or limited in maneuvering the contents, they will lose interest, and this is directly linked to lowering of their interest in the game contents. Discussing the relationship between Ten Usability Heuristics and Game Heuristics, Melissa A. Federoff made the following statements about game interface and game mechanics[Table 5].

TABLE VI. USER CONTROL AND FREEDOM

\begin{tabular}{|l|l|}
\hline \multirow{2}{*}{1} & Game Interface \\
\cline { 2 - 2 } & $\begin{array}{l}\text { Controls should be customizable and default to industry standard } \\
\text { settings }\end{array}$ \\
\hline \multirow{2}{*}{2} & Game Mechanics \\
\cline { 2 - 3 } & Feedback should be given immediately to display user control \\
\hline
\end{tabular}

Melissa A. Federoff's "Recognition rather than recall" emphasizes the importance of intuitive interface which minimizes the amount of information that users have to remember in order to use the interface(Federoff, 2002). The game heuristics related to this are as follows:

TABLE VII. RECOGNITION RATHER THAN RECALL

\begin{tabular}{|l|l|}
\hline \multirow{2}{*}{1} & Game Interface \\
\cline { 2 - 3 } 2 & Controls should be intuitive and mapped in a natural way \\
\hline \multirow{2}{*}{2} & Game Interface \\
\cline { 2 - 2 } & Minimize control options \\
\hline \multirow{2}{*}{3} & Game Interface \\
\cline { 2 - 3 } & $\begin{array}{l}\text { Follow the trends set by the gaming community to shorten the } \\
\text { learning curve }\end{array}$ \\
\hline 4 & Game Interface \\
\hline
\end{tabular}

\begin{tabular}{|l|l|}
\hline & Do not expect the user to read a manual \\
\hline \multirow{2}{*}{5} & Game Mechanics and Play \\
\cline { 2 - 3 } & Get the player involved quickly and easily \\
\hline
\end{tabular}

When the items related to "Ease of use" and "learnability of operation" are put together from "Ten Usability Heuristics" and "Game Heuristics," we learn the following important pieces of information about usability. See Table 7.

TABLE VIII. ITEMS RELATED TO USABILITY EVALUATION IN EXISTING HEURISTICS

\begin{tabular}{|c|c|c|}
\hline \multirow[b]{2}{*}{ Ease of use } & a. & User control and freedom \\
\hline & b. & $\begin{array}{l}\text { Feedback should be given immediately to display } \\
\text { user control }\end{array}$ \\
\hline \multirow{5}{*}{ Learnability } & c. & Recognition rather than recall \\
\hline & d. & $\begin{array}{l}\text { Controls should be intuitive and mapped in a } \\
\text { natural way }\end{array}$ \\
\hline & e. & Minimize control options \\
\hline & f. & Do not expect the user to read a manual \\
\hline & g. & Get the player involved quickly and easily \\
\hline
\end{tabular}

The criteria used in this study for usability evaluation are based on the items listed in Table 7. In the related item part of the table 8 , an association item with the table 7 is written.

TABLE IX. CONTENT OF THE QUESTIONNAIRE

\begin{tabular}{|c|c|c|c|}
\hline Criteria & No. & Content & $\begin{array}{l}\text { Related } \\
\text { items(Table } \\
\text { VII) }\end{array}$ \\
\hline \multirow{2}{*}{ Ease of use } & 1 & $\begin{array}{l}\text { Is free inputting possible for the control } \\
\text { interface that implements each command? }\end{array}$ & a. \\
\hline & 2 & $\begin{array}{l}\text { Can users get clear feedback of actions } \\
\text { that are on progress according to } \\
\text { command? }\end{array}$ & b. \\
\hline \multirow{5}{*}{ Learnability } & 3 & $\begin{array}{l}\text { Is it easy to learn how to use the control } \\
\text { interface of the gamer? }\end{array}$ & f. \\
\hline & 4 & $\begin{array}{l}\text { Is it easy to remember the game's control } \\
\text { interface? }\end{array}$ & c. \\
\hline & 5 & $\begin{array}{l}\text { Can you expect the users who have not } \\
\text { learned how to use the commands to use } \\
\text { the commands and play the game? }\end{array}$ & $\mathrm{c}, \mathrm{d}$ \\
\hline & 6 & $\begin{array}{l}\text { Is a natural and intuitive operation } \\
\text { interface appropriate for inputting } \\
\text { commands being applied? }\end{array}$ & $\mathrm{c}, \mathrm{d}, \mathrm{g}$. \\
\hline & 7 & $\begin{array}{l}\text { Is the number of moves required for } \\
\text { implementing the commands appropriate? }\end{array}$ & e. \\
\hline
\end{tabular}

\section{Result of Evaluation}

As shown in Fig. 12, the result of usability evaluation indicated that the method proposed in this study gave a higher degree of satisfaction about the feedback on the game in progress because making hand motions in the air (space) is all that users need to do to get the information they want about the positions and interactions. Thus, the feedback on the result of 
hand motion in space is delivered more intuitively than the existing multi-touch screen method. However, touching the surface of the touch-screen directly for inputting gave a higher degree of satisfaction to users than touching the air space. This is attributed to the fact that, in general, users have been frequently exposed to the existing method of inputting. This problem can be overcome readily through the learning process of the interface.

TABLE X. RESUlT OF USABILITY EVALUATION - EASE OF USE

\begin{tabular}{|c|l|l|c|c|}
\hline Characteristics & Item & Content & $\begin{array}{c}\text { Proposed } \\
\text { system }\end{array}$ & $\begin{array}{c}\text { Existing } \\
\text { system }\end{array}$ \\
\hline Ease of use & $\begin{array}{l}\text { Progress } \\
\text { feedback }\end{array}$ & $\begin{array}{c}\text { Is the feedback of the } \\
\text { result of inputting clear } \\
\text { and correct? }\end{array}$ & 4.48 & 3.78 \\
\cline { 2 - 5 } & Free input & $\begin{array}{l}\text { Is it possible to input } \\
\text { easily and freely the } \\
\text { operational interface that } \\
\text { carries out each } \\
\text { command? }\end{array}$ & 4 & 4.76 \\
\hline
\end{tabular}

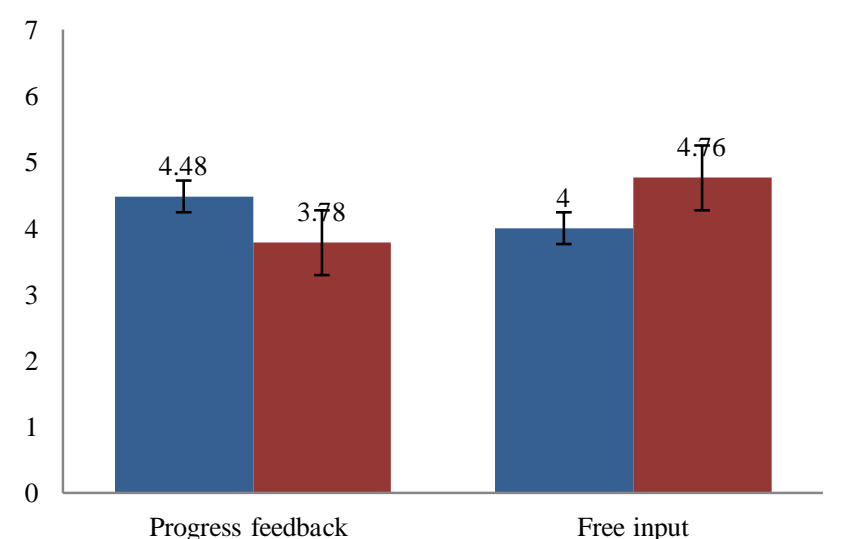

- Proposed System $\quad$ Existing System

Fig. 12. Result of usability evaluation - ease of use.

As shown in Fig. 13, the result of usability evaluation on the ease of use shows that the proposed method gives a higher degree of satisfaction than the existing method. This means that the space multi-interaction interface is easier and more natural to use than the existing system. For users who are exposed to it for the first time, however, the learnability of the new space interaction interface is somewhat lower than that of the existing multi-touch interaction system. But once users become familiar with the new system after the initial learning process, the functions are easier and more natural to remember and decrease the number of interaction gestures to implement the commands.
TABLE XI. RESULT OF USABILITY EVALUATION - LEARNABILITY OF USE

\begin{tabular}{|c|c|c|c|c|}
\hline Subject & Category & Content & $\begin{array}{c}\text { Proposed } \\
\text { System }\end{array}$ & $\begin{array}{l}\text { Existing } \\
\text { System }\end{array}$ \\
\hline \multirow{5}{*}{$\begin{array}{c}\text { Learnability of } \\
\text { Use }\end{array}$} & Learnability & $\begin{array}{l}\text { Is it easy to learn how to } \\
\text { use the interface? }\end{array}$ & 5.96 & 5.38 \\
\hline & Memory & $\begin{array}{l}\text { Is it easy to remember } \\
\text { the game interface? }\end{array}$ & 5.7 & 6.12 \\
\hline & $\begin{array}{l}\text { Operative } \\
\text { predication }\end{array}$ & $\begin{array}{l}\text { Is it possible to anticipate } \\
\text { and be able to use the } \\
\text { functions that the users } \\
\text { have not learned? }\end{array}$ & 4.34 & 4.9 \\
\hline & Naturalness & $\begin{array}{l}\text { Is a natural and intuitive } \\
\text { control interface applied } \\
\text { to motions and gestures } \\
\text { required to input the } \\
\text { command? }\end{array}$ & 4.64 & 5.6 \\
\hline & $\begin{array}{l}\text { Command } \\
\text { count }\end{array}$ & $\begin{array}{l}\text { Is the number of starting } \\
\text { gestures to implement the } \\
\text { command appropriate? }\end{array}$ & 4.94 & 5.32 \\
\hline
\end{tabular}

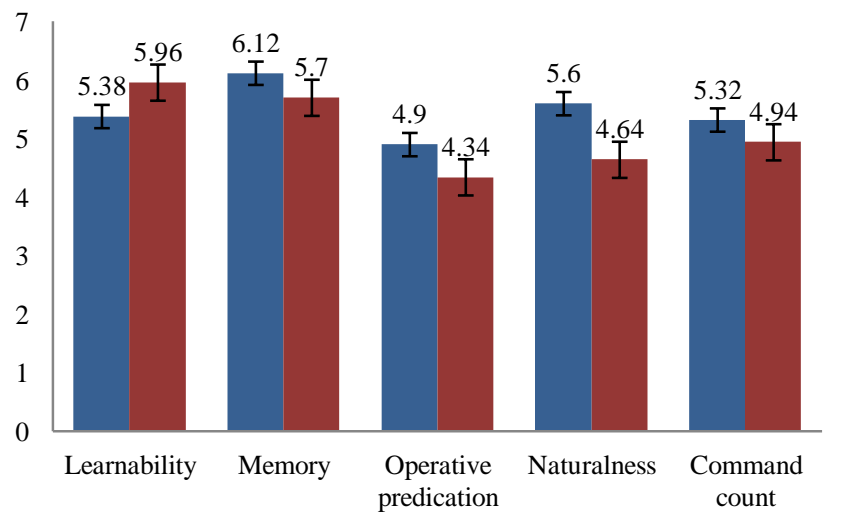

- Proposed System घ Existing System

Fig. 13. Result of usability evaluation - Learnability of operation mode

Table 12 lists the result of statistical verification using ttest. The t-test is the statistical method which is necessary when it grasps whether the average difference between the two groups determine whether statistically significant. At the confidence level of $95 \%$, value $p$ is lesser than 0.05 in all items evaluated. Therefore, there is significant difference between the items evaluated. In other words, since the null hypothesis is rejected, there is statistically significant difference between the mean average of the traditional method and that of the proposed method. Statistics and the level (significance level) to compare and judge to reject the null hypothesis when the hypothesis is "statistically significant" are called. In other words, the probability that the result is not enough to think that mere coincidence is meaningful. 
TABLE XII. RESULT OF STATISTICAL VERIFICATION

\begin{tabular}{|c|c|c|c|c|c|c|}
\hline \multirow{2}{*}{ Measures } & \multicolumn{2}{|l|}{ Proposed system } & \multicolumn{2}{|c|}{ Existing system } & \multirow{2}{*}{ t } & p \\
\cline { 2 - 6 } & Mean & S.D & Mean & S.D & & \\
\hline $\begin{array}{c}\text { Progress } \\
\text { feedback }\end{array}$ & 4.48 & 1.403 & 3.78 & 1.282 & -3.183 & 0.003 \\
\hline Free input & 4 & 1.385 & 4.76 & 1.379 & 3.040 & 0.004 \\
\hline Learnability & 5.38 & 1.524 & 5.96 & 1.049 & 3.529 & 0.001 \\
\hline Memory & 6.12 & 0.872 & 5.7 & 1.344 & -2.680 & 0.010 \\
\hline $\begin{array}{c}\text { Operative } \\
\text { prediction }\end{array}$ & 4.9 & 1.329 & 4.34 & 1.710 & -2.527 & 0.015 \\
\hline \begin{tabular}{c} 
Naturalness \\
\hline $\begin{array}{c}\text { Commands } \\
\text { count }\end{array}$
\end{tabular} & 5.6 & 1.355 & 4.64 & 1.935 & -4.106 & 0.000 \\
\hline
\end{tabular}

However, in the overall evaluation, the proposed method showed a higher evaluation result than the existing method as shown in Fig. 14. As shown in the experimental result, it is shown from the averages that each result difference is displayed. In the Progress feedback, Memory, Operative prediction, Naturalness, and Commands count items, the proposed system received the higher evaluation but the existing system received the higher evaluation in the Learnabilty and Free input items.

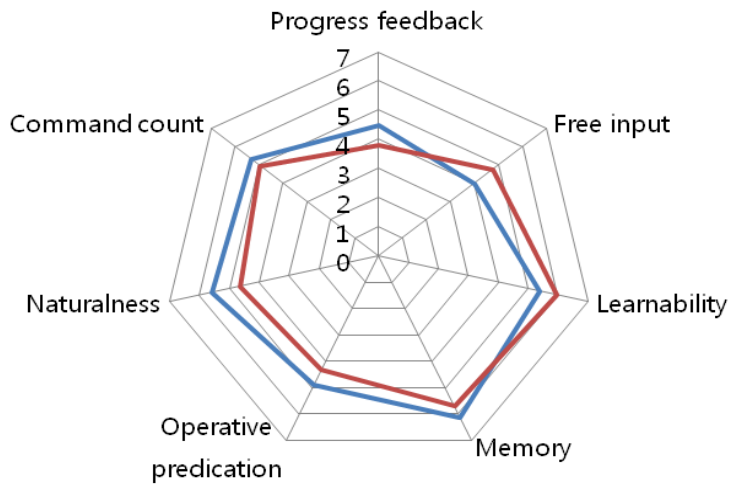

—Proposed System —Existing System

Fig. 14. Scale analysis graph

\section{CONCLUSION}

This paper proposes a spatial multi-interaction system to offer an interactive area for multiple users to interact in an ambient display environment. The proposed system creates an interaction surface on which users can interact through the IRLEDs Array Bar. Thus a variety of interactions are offered. The users are in the interactive space when they stand in arm's length and touch the interaction surface that uses light rays from the IR-LEDs Array Bar. In a ubiquitous ambient environment, the proposed system offers an interactive display system and a user interface method with which users can interact by simple touch motions with the aid of sensing devices for recognition. A performance test indicated that the proposed interface can be as effective as the existing multitouch screen. With ample explanation on how to operate the system, users can learn various interaction information as they go through the entire operation process, and when the screen size grows larger eventually, multiple users can use the system simultaneously. The system has excellent expandability since it can be operated in a small area as well as a large area without any restrictions, and users can experience many different contents directly by space-touching the interactive surface.

\section{ACKNOWLEDGMENT}

This research was financially supported by the Program in the Regional Innovation Center conducted by the Ministry of Trade, Industry and Energy of the Korean Government.

\section{REFERENCES}

[1] Aarts, E. (2003). Technological Issues in Ambient Intelligence; Emile Aarts and Stefano Marzano (eds.). The New Everyday Visions of Ambient Intelligence, 12-17.

[2] Barrée, R., Chojecki, P., Leiner, U., Müuhlbach, L., \& Ruschin, D. (2009). Touchless Interaction-Novel Chances and Challenges. In Proceedings of the 13th international Conference on Human-Computer Interaction, Part II: Novel interaction Methods and Techniques (San Diego, CA, July 19 - 24, 2009). Lecture Notes In Computer Science, Vol. 5611, 161-169.

[3] Bellucci, A., Malizia A., Diaz P., \& Aedo, I.(2010). Don't touch me: multi-user annotations on a map in large display environments. AVI '10: Proceedings of the International Conference on Advanced Visual Interfaces, 391-392.

[4] Baek, S.H., Kim, J.S. \& Kim, T.Y. (2005). Infrared LED Tracking and Aim Position Calibration for an Arcade Gun. Journal of KGS(Korea Game Society), 5(1), 3-10.

[5] Choi, W., Kim , T. Y. \& Lim, C. S. (2007). A Rehabilitation Training System Using the infrared LED based Motion Analysis. Journal of KCGS(Korea Computer Graphics Society), 13(4), 29-36.

[6] Choi, S. E., Jung, J. W. \& Seo, Y. W. (2008). Technology Trend and Application for Tabletop Device and Interactive Wall Display. Journal of KIISE(Korean Institute of Information Scientists and Engineers), 26(3), 5-14.

[7] Federoff, M. A. (2002). Heuristics and Usability Guidelines for the Creation and Evaluation of Fun in Video Games. Unpublished master's thesis, Department of Telecommunications of Indiana University.

[8] Hong, D., \& Woo, W.(2006). A 3D Vision-Based Ambient User Interface. International Journal of Human-Computer Interaction, 15327590, Volume 20, Issue 3, 271 - 284.

[9] Hong, S. S., Seo, J. K., Ko, C. S. \& Ahn, H. I. (2009). Implementation of Intuitive Method for Controlling Multi-device with Universal Remote Controller. Proceedings of KHCI 2009, 646-649.

[10] Holmlid, S. \& Björklind, A. (2003). Ambient Intelligence to go, AmiGo white paper on mobile intelligent ambience. Research Report SAR-0303.

[11] IST Advisory Group. (2003). Ambient intelligence: From vision to reality. Available from ftp://ftp.cordis.lu/pub/ist/docs/istagist2003_consolidated_report.pdf.

[12] Johanson, B. (2002). The Interactive Workspaces Project: Experiences with Ubiquitous Computing Rooms. Pervasive Computing Magazine Special Issue on Systems, Vol.2, 67-74.

[13] Kim, Y.M. \& Kim J. (2009). IRTS(Infrared Tracking System) for Interactive Multimedia Contents. Journal of EASKO, 1(1), 51-59.

[14] Lee, J.C.(2008). Hacking the Nintendo Wii Remote, IEEE Pervasive Computing, 7(3), 39-45.

[15] Murata, A.(2006). Eye-gaze input versus mouse: Cursor control as a function of age. International Journal of Human-Computer Interaction, 1532-7590, Volume 21, Issue 1, 1- 14. 
[16] Nielsen, J. (1994). Heuristic evaluation. In Nielsen, J., and Mack, R.L. (Eds.), Usability Inspection Methods. John Wiley \& Sons, New York, NY.

[17] Nielsen, J. (1993). Usability Engineering. published by Morgan Kaufmann, San Francisco.

[18] Park, J.S. \& Park, J. (2008). LED-bar: An Interaction Tool for Large Display Games. Journal of KSCG(Korean Society for Computer Game), No $15,49-54$.

[19] Russell, D. M., Streitz, N. \& Winograd, T. (2005). Building Disappearing Computers. Communications of the ACM, 48(3), 42-48.

[20] Stephanidis , C.(2009). Designing for All in Ambient Intelligence Environments: The Interplay of User, Context, and Technology. International Journal of Human-Computer Interaction, 1532-7590, Volume 25, Issue 5, $441-454$

[21] Streitz, N. A. (2007). From Human-Computer Interaction to HumanEnvironment Interaction. ERCIM UI4ALL Ws 2006, LNCS 4397, 3-13.

[22] Streitz, N., Geißler, J., \& Holmer, T. (1998). Roomware for Cooperative Buildings: Integrated Design of Architectural Spaces and Information Spaces. Proceedings of CoBuild '98, Darmstadt, Germany, LNCS Vol.1370, Heidelberg, Germany, Springer, 4-21.
[23] Streitz, N., Tandler, P., Müller-Tomfelde, C., \& Konomi, S. (2001). Roomware: Towards the Next Generation of Human-Computer Interaction based on an Integrated Design of Real and Virtual Worlds. Human-Computer Interaction in the New Millennium, Addison-Wesley, 553-578.

[24] Tandler, P. (2004). The BEACH application model and software framework for synchronous collaboration in ubiquitous computing environments. Journal of Systems and Software, 69(3), 267-296.

[25] Vaughan-Nichols, S. J.(2009). Game-Console Makers Battle over Motion-Sensitive Controllers. Journal Computer, 42(8), 13-15.

[26] Vogel, D. \& Balakrishnan, R. (2004). Interactive Public Ambient Displays : Transitioning from Implicit to Explicit Public to Personal, Interaction with Multiple Users. Proceedings of UIST 2004, 137-146.

[27] Wisneski, C., Ishii, H., Dahley, A., Gorbet, M., Brave, S., Ullmer, B., \& Yarin, P. (1998). Ambient Displays: Turning Architectural Space into an Interface between People and Digital Information. Proceedings of CoBuild '98, Darmstadt, Germany, LNCS Vol.1370, Heidelberg, Germany, Springer, 22-32.

[28] Yoon, J.W., Hong, J.H. \& Cho, S.B. (2009). MyWorkspace: VR Platform with an Immersive User Interface. Proceedings of KHCI 2009, $52-55$. 